\title{
Field test research for optimization design under condition of complex Soil Stratum
}

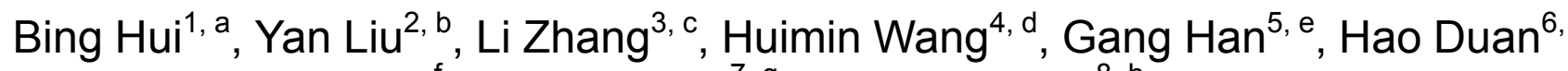 \\ , Zhangjian $\mathrm{Yu}^{7, g}$, Wenjun Zhang ${ }^{8, \mathrm{~h}}$ \\ 1,2,4,5,6,7,8 Shandong Zhengyuan Construction Engineering Co., Ltd, Ji'nan,250101,China \\ ${ }^{3}$ China Shandong Urban Construction Vocational Collage, Jinan 250014, China; \\ ayzxcdd@sohu.com, ${ }^{\mathrm{b}}$ 25215026@qq.com, ${ }^{\mathrm{c}} 641928374 @ q q . c o m,{ }^{d}$ njuwhm@sohu.com,

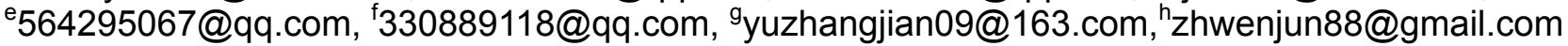

Keywords: foundation, optimization design, district control measures, field test

\begin{abstract}
It is highly important to choose suitable of the foundation in underground engineering. With the engineering, the foundation is made of gravelly soil, which distributed discontinuity and had bad uniformity. Drilling method, dynamic sounding method and deep plate loading test were applied, combined with previous investigation results, geotechnical parameters were defined and optimization designed. Upon the result of field tests, some control measures were made to improve the condition of foundation .District control measures were suggested to be made. The silt clay layer(4) under the basement of $1^{\#}$ building's east A- area, pile pier was suggested to be set up, the pier's bottom should be set in cement gravel(5)strata, and should made of C15 plain concrete, raft foundation should also be applied. In other areas, soil upon cement gravel(5)strata were suggested to be dig out, and replaced with rubble concrete to the level of foundations bottom, also should applied raft foundation. Foundation strength and deformation were up to the mustard according to the result of numerical simulation. The optimization design not only supplied the technical demand well, but also reduced a lot of construction schedule and save cost. This study supplied some theory and technical guides to closely engineering.
\end{abstract}

\section{Introduction}

With the improvement of the economy level and scientific technology in China, underground space projects are developing quickly. Fully considering the structural reliability of underground space, easy construction, economic rationality and other factors, foundation scheme optimization choose become a important problem in the engineering. At present, most of the foundation scheme is diversification and integration in the project ${ }^{[1-2]}$.

In view of the foundation scheme selection and optimization, scholars at home and foreign carried on the thorough research and engineering practice ${ }^{[3-5]}$. Zhou feng et al ${ }^{[6]}$ has carried on the numerical analysis, which based on the analysis of the experimental results of natural foundation with variable stiffness cushion working characteristic. Zhao Ming-hua et al ${ }^{[7]}$ based on the similarity theory, designed and completed a large geotechnical reinforced cushion, sand well, medium material pile and flexible pile of nine groups of model test of composite foundation, which were analyzed in reinforcement effect. Liu Jin-li et al ${ }^{[8]}$, in considering the upper structure, raft, the interaction of pile and soil, and the characteristics of the work, the variable stiffness leveling design was put forward. Gong Xiao-nan ${ }^{[9]}$ putted forward the idea of composite foundation in the generalized composite foundation theory problems and settlement control design. Chen Long-zhu et al ${ }^{[10]}$, made finite element analysis about reinforced concrete raft of the variable stiffness composite foundation treatment. Zhang hua et al ${ }^{[11]}$, on soil cement mixing composite foundation reinforcement scheme optimization of finite element analysis also got similar results. 


\section{Building structure and formation characteristics}

\subsection{Requirements of building structure}

A section of $1^{\#}$ building in a project, which is shear wall structure and safety class II, has 32 layers on the ground floor, column spacing $3 \mathrm{~m}$, and the plane size $73.7 \mathrm{~m} \times 16.5 \mathrm{~m}$. The building has 3 basements, and base elevation is $40.00 \mathrm{~m}$. Base load of the building is $450 \mathrm{KN} / \mathrm{m}^{2}$, and the base reaction force is $480 \mathrm{kPa}$ of standard combination, which is $440 \mathrm{kPa}$ of quasi-permanent combination. The elevation of underground garage foundation is $39.5 \mathrm{~m}$, which mostly in the (3) layer of silty clay and (3) layer of gravel soil, partial in the (5) layer of cemented gravel layer, and (3) 1 layer of gravel soil has complexity and inhomogeneity. In order to make a more stable foundation evenly, reducing uneven settlement, foundation program optimization need to be done.

\subsection{Distribution of gravel soil layer}

According to geotechnical investigation report shows that gravel soil layer is described as: gray, wet, medium density, limestone rock, content of $40 \% \sim 60 \%, \varphi 1 \sim 5 \mathrm{~cm}$, greater than $10 \mathrm{~cm}$ of the largest, poor roundness, hypo-edge angle and mild round. Partial calcareous conglomerates cemented thin, hard, and partial lens-shaped profile. The thickness is $0.90 \sim 11.60 \mathrm{~m}$, average 4.40 m.

Analysis of existing reports and coring site shows (Figure1) that gravel soil has the characteristics of relatively poor uniformity, distribution not continuous and so on.

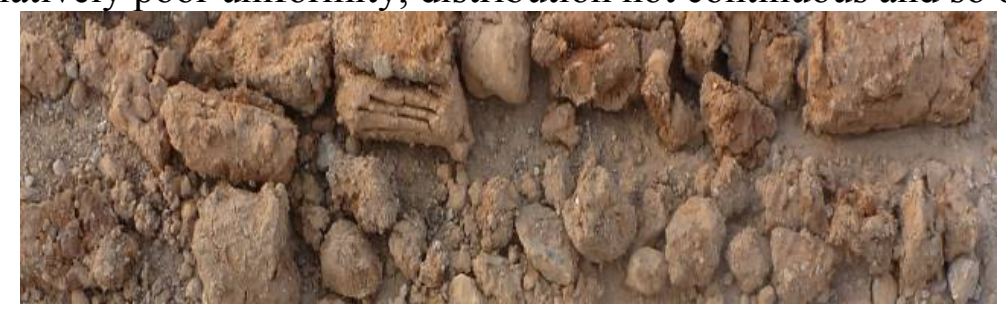

Fig. 1 Field coring test

\section{Field test for optimal design of foundation.}

In order to further clarify physical and mechanical parameters of the (3) layer soil under $1^{\#}$ floor, field test was needed. For the characteristics of distribution of gravelly soil, adopted drilling exploration, static cone, bearing capacity test to optimal design the plan which using layer soil as foundation bearing layer. In-situ test, included 3 drilling exploration, 4 heavy dynamic sounding test and 3 bearing capacity.

\subsection{Field exploration experiment}

Based the arrangement, combined with the site conditions, arranged 3 drilling hole, depths were $19.0 \mathrm{~m}, 15.0 \mathrm{~m}$ and $15.0 \mathrm{~m}$, using XY-100 hydraulic robot rotary drill, above the ground water table drilling without water, under the ground water table hole wall of anchor is sustained by slurry, diameter of the hole must greater than $110 \mathrm{~mm}$.

\subsection{In-situ severe cone dynamic penetration test}

Weight of the heavy hammer was $63.5 \mathrm{~kg}$ and falling distances was $76 \mathrm{~cm}$, diameter of the drill pipe was $42 \mathrm{~mm}$, experiments in detritus soil, cleared the hole before test, severe cone dynamic penetration test in one hole each time, recorded the blow counts N63.5 each time when injected 10 $\mathrm{cm}$ among continuously injection $50 \mathrm{~cm}$.(figure 2 ) 


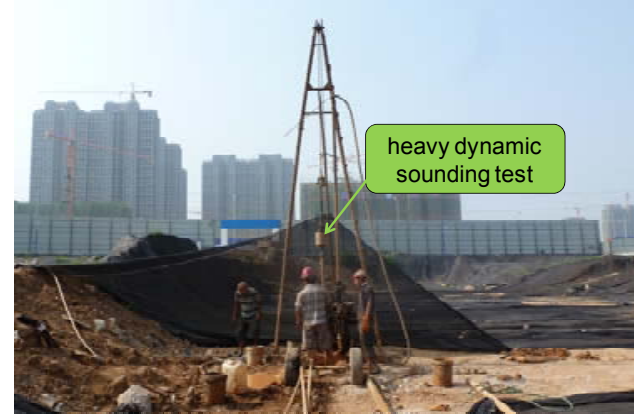

Fig. 2 Severe cone dynamic penetration test

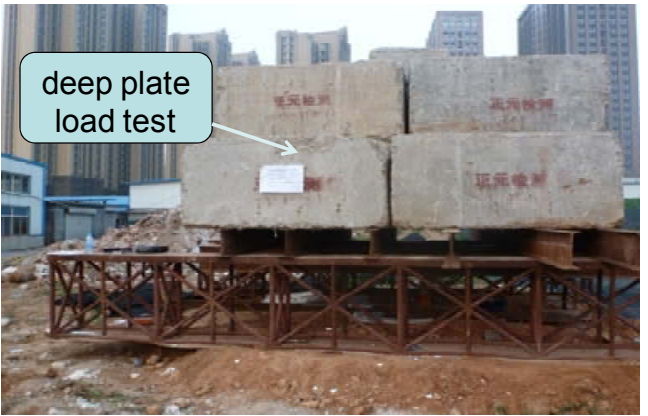

Fig. 3 Deep plate load test

\subsection{In-situ deep plate load test}

Adopted bearing plate whose diameters was $800 \mathrm{~mm}$, the top of test pit was $1000 \mathrm{~mm}$ and bottom was $900 \mathrm{~mm}$, should avoid disturbed the bottom soil, maintain its structure and natural water content, lay sand cushion not exceeding $20 \mathrm{~mm}$ under the bearing plate, multi-stage loading gave by reaction frame providing counterforce, measured displacement and loads(figure 3).3 in-situ $\mathrm{SZ1,SZ2}$ and SZ3 deep plate load test was implemented, depths were $6.5 \mathrm{~m} 、 7.0 \mathrm{~m} 、 7.5 \mathrm{~m}$.

\section{Optimization design of foundation}

\subsection{Analysis of the field test results}

During field investigation, there were 3 drilling holes, and 4 group heavy dynamic penetration tests and 3 group deep plate load tests had been performed on this site from 07.01.2014 to 07.28.2014, for almost a month. The stratigraphic distribution of the drilling holes and results of the heavy dynamic penetration tests were summarized (Table 1). P-S curves of deep plate loading tests of SZ1, SZ2, SZ3 were gained (Fig 4).

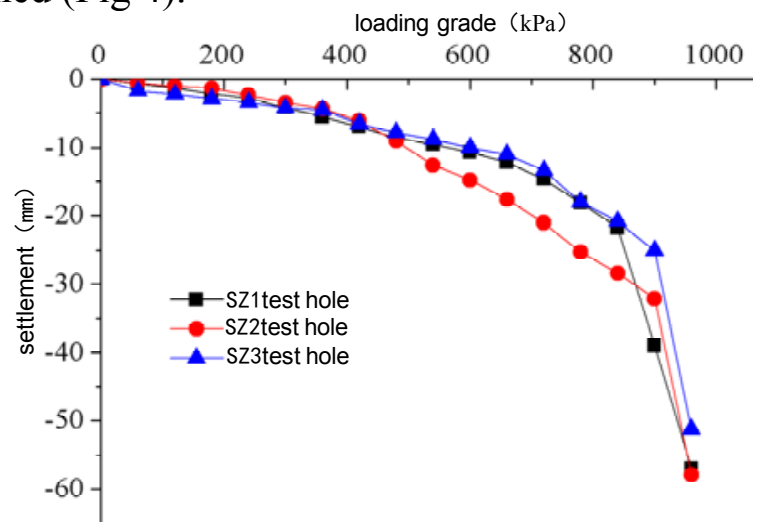

Fig. 4 The P-S curve of in-situ deep plate load test

Table 1 Stratigraphic distribution of the drilling holes and results of the heavy dynamic penetration tests

\begin{tabular}{ccccccc}
\hline & \multicolumn{3}{c}{ Strata thickness $(\mathrm{m})$} & \multicolumn{3}{c}{$\begin{array}{c}\text { Results of the heavy dynamic penetration test } \\
\left(\text { deep }-\mathrm{N}_{120}\right)\end{array}$} \\
\hline & $\mathrm{BZ1}$ & $\mathrm{BZ2}$ & $\mathrm{BZ3}$ & $\mathrm{BZ1}$ & $\mathrm{BZ2}$ & $\mathrm{BZ3}$ \\
(1) Miscellaneous fill & - & 2.30 & 2.50 & - & - & - \\
(2) Loessial silty clay & 4.00 & 4.40 & 1.00 & - & - & - \\
(3) Silty clay & 3.20 & 1.20 & 1.90 & - & - & $8.10-11$ \\
(3) Gravel soil & - & 1.30 & 5.10 & - & $9.00-26$ & $9.10-13$ \\
(4) Silty clay & - & 4.20 & 3.00 & - & - & - \\
(5) Cemented gravel & 5.40 & 1.60 & 1.50 & - & - & - \\
(5) Gravel soil & 3.40 & & - & - & - & - \\
(6) Completely weathered diorite & 3.0 & & - & - & - & - \\
\hline
\end{tabular}


According to the field test results, the measured bearing capacity characteristic values for the 3 group deep plat load tests in (3) 1 gravel soil are $437.5 \mathrm{kPa}, 420 \mathrm{kPa}$ and $420 \mathrm{kPa}$ respectively. Because the rang of bearing capacity characteristic values is less than $30 \%$ of its average, the bearing capacity characteristic measured value is $425.8 \mathrm{kPa}$ in A-step of Building $1^{\#}$.

\subsection{Deformation modulus and foundation modulus}

The deformation modulus of soil should be calculated according to the initial straight line segment of P-S curve and the elastic theory of homogeneous isotropic semi infinite elastic medium. The deformation modulus of the deep plate load tests can be calculated from the following formula:

$$
E_{0}=\omega \frac{p d}{s}
$$

The foundation modulus can be obtained by the Slope of straight line segment in P-S curve, according to the following formula:

$$
K_{v}=\frac{p}{s}
$$

According to the field test results, the deformation modulus and the foundation modulus of the (3) 1 gravel soil are $21.69 \mathrm{MPa}$ and $61.62 \times 10^{6} \mathrm{~Pa} / \mathrm{m}$ respectively.

\subsection{Analysis of soft substratum}

When there is soft substratum in the range of soil stressed zone, according to Code for design of building foundation(GB50007-2011)Article 5.2.7 calculation formula:

$$
p_{z}+p_{c z} \leq f_{a z}
$$

To rectangular foundation:

$$
\begin{gathered}
p_{z}=\frac{l b\left(p_{k}-p_{c}\right)}{(b+2 z \tan \theta)(l+2 z \tan \theta)} \\
p_{c z}=\gamma_{0} d+\gamma z \\
f_{a z}=f_{a k}+\eta_{d} \gamma_{m}(d-0.5)
\end{gathered}
$$

According to the investigation report, Using the data of Drilling $10^{\#}$ to calculate:

$$
?=75.10 \mathrm{~m}, \quad b=17.90 \mathrm{~m}, \quad \boldsymbol{p}_{\mathbf{z}}=510 \mathrm{kPa}, \quad p_{\varepsilon}=60 \mathrm{kPa}, \quad \mathrm{z}=40-30=10 \mathrm{~m}, \quad \mathrm{z} / \mathrm{b}=10 / 17.9=0.559,
$$

$\boldsymbol{t}_{\boldsymbol{x}} / \boldsymbol{k}_{\boldsymbol{a}}=50 / 30=1.667, \quad \theta=21.3$

$$
p_{z}+p_{c z}=480.6 \mathrm{kPa} \quad f_{a z}=f_{a k}+\eta_{d} \gamma_{m}(d-0.5)=867 \mathrm{kPa}
$$

By the calculation analysis shows that soft substratum meet the requirements.

\subsection{Foundation bearing capacity calculation}

When the width of the rectangular foundation of the proposed building is more than $3 \mathrm{~m}$, or embedment depth is greater than $0.5 \mathrm{~m}$, the characteristic value of sub grade bearing capacity determined through the load test or other in-situ test, experience and other methods, need to be adopted under type fixed:

$$
f_{a}=f_{a k}+\eta_{b} \gamma(b-3)+\eta_{d} \gamma_{w}(d-0.5)
$$

The type of symbol with the formula 1.

By the calculation:

$$
\begin{aligned}
& f_{a}=f_{a k}+\eta_{b} \gamma(b-3)+\eta_{d} \gamma_{w}(d-0.5) \\
& =999.50(\mathrm{kPa})
\end{aligned}
$$

The requirements of the base reaction (standard forming) is $480 \mathrm{kPa}$. So the foundation bearing capacity satisfy the design requirements.

\section{5 settlement calculation}

According to Technical code for tall building raft foundations and box foundations(JGJ 6-2011)Settlement calculation formula is as follows.

$$
s=p_{k} b \eta \sum_{i=1}^{n} \frac{\delta_{i}-\delta_{i-1}}{E_{0 i}}
$$


The suitable formula for settlement calculation depth ${ }^{Z_{n}}$ is as follows.

$z_{n}=\left(z_{m}+\xi b\right) \beta$

Table 2 The calculation of foundation settlement

\begin{tabular}{ccc}
\hline $\begin{array}{c}\text { number of holes } \\
10\end{array}$ & $\begin{array}{c}\text { soil layer } \\
\text { (3) } 1 \text { gravel soillayer } \\
\text { 5) unconsolidated gravel bed }\end{array}$ & $\begin{array}{c}\text { settlement }(\mathrm{mm}) \\
74.77\end{array}$ \\
13 & $\begin{array}{c}\text { cyclopean concrete by changing and filling } \\
\text { 5) unconsolidated gravel bed } \\
\text { cyclopean concrete by changing and filling } \\
\text { 5) unconsolidated gravel bed } \\
22\end{array}$ & 51.59 \\
& $\begin{array}{c}\text { cyclopean concrete by changing and filling } \\
\text { 5) unconsolidated gravel bed }\end{array}$ & 40.41 \\
\hline
\end{tabular}

Through calculating that ${ }^{Z_{n}}$ is $7.6 \mathrm{~m}$ and settlements is $40.41 \sim 74.77 \mathrm{~mm}$. They all meet the requirements.

\section{Summary}

(1) Due to distributed discontinuity and had bad uniformity, drilling method, dynamic sounding method and deep plate loading test were applied, combined with previous investigation results, geotechnical parameters were defined and optimization designed.

(2) Under the analysis of field test results, the foundation weak layer meet the requirements, but as a foundation bearing layer for gravel soils need for processing. Upon the result of field tests, some control measures were made to improve the condition of foundation .District control measures were suggested to be made.

(3) The silt clay layer(4 under the basement of $1^{\#}$ buildings east A- area, pile pier was suggested to be set up, the piers bottom should be set in cement gravel(5) strata, and should made of C15 plain concrete, raft foundation should also be applied. In other areas, soil upon cement gravel(5) strata were suggested to be dig out, and replaced with rubble concrete to the level of foundations bottom, also should applied raft foundation.

(4) The optimization design take comprehensive test means not only supplied the technical demand well, but also reduced a lot of construction schedule and save cost. This study supplied some theory and technical guides to closely engineering.

\section{Acknowledgements}

The work is supported by the Young Technology Foundation Financial Aid Project of Shandong Local. Li Zhang is the corresponding author.

\section{References}

[1] GONG Xiaonan. Theory of composite foundation and engineering application[M]. Beijing: China Architecture and Building Press, 2002: 45-67.

[2] YANG Guanghua, LI Deji, GUAN Dashu. Optimization design of rigid pile composite foundation[J]. Chinese Journal of Rock Mechanics and Engineering, 2011, 30(4): 818-825.

[3] Randolph M F. Science and empiricism in pile foundation[J]. Geotechnique, 2003, 53(10):847-875.

[4] CHI Yuejun, SONG Erxiang, CHEN Zhaoyuan. An simplified method for settlement of rigid-pile composite foundation[J]. China Civil Engineering Journal, 2003, 36(11): 19-23.

[5] XU Dong-sheng, WANG Ren, MENG Qing-shan, et al. Field test analysis of dynamic 
consolidation and replacement sand pile on marine soft soil[J]. Rock and Soil Mechanics,2009, 30(12): 3831-3836.

[6] ZHOU Feng, ZAI Jinmin, MEI Guoxiong Concept and method of variable rigidity bedding for subgrade[J]. Building Science Research of Sichuan, 2009, 35(4): 116-119.

[7] ZHAO Ming-hua, LONG Jun, ZHANG Ling, et al. Comparative analysis of model tests on different types of composite foundations[J]. Chinese Journal of Geotechnical Engineering, 2013, 35(4): 611-618.

[8] Liu Jinli, Chi Lingquan. The modified model of pile-soil deformation calculation and variable rigidity design method for balance settlement[J]. Chinese Journal of Geotechnical Engineering, 2000, 22(2): 151-157.

[9] GONG Xiaonan. Development of composite foundation and its application to highrise building[J]. China Civil Engineering Journal, 1999, 32(6).

[10]Chen Longzhu, Liang Fayun, Ding Yi. Analysis of compound foundation of variable rigidity with fem[J]. Industrial Construction, 2003, 33(11): 1-4.

[11]ZUO Wei, LI Jun-niu. Finite element analysis of Pi-l soil stress ratio of Embankment filled with soil and composite ground[J]. Journal of Hebei Institute of Architectural Science and Technology, 2006, 23(2): 46-49. 